\title{
PRODUCTION OF CAVITIES WITH APPLICATION OF FREE CORE SOLENOID
}

\author{
1Ján MORAVEC \\ 1University of Žilina, Žilina, Slovak Republic, EU, jan.moravec@fstroj.uniza.sk
}

https://doi.org/10.37904/metal.2020.3464

\begin{abstract}
The paper deal with the unconventional method of creating cavities in samples. There is also described the principle of system for creating experimental samples. In other parts is work focus on free-core forming of cavities in lead samples. Based on the idea of the experimental device was this constructed and the research was carried out. An important part of the experimental device is the electrical circuit, where a magnetic field (impulse) is created, which forms the experimental samples. With free-core forming, lead samples of square shape with dimensions of $35 \times 35 \mathrm{~mm}$ and thickness of $7 \mathrm{~mm}$ were formed. The results obtained in the experiments show that such a molding method is suitable for several reasons. The first is the speed of the process. In this case it is $0.03 \mathrm{~s}$. The second advantage is in terms of ease of automation using this type of forming. Quite a simple solution with application of magnetic field ensures accurate, fast and high-quality cavity formation in metal materials. The results achieved confirm the suitability of the solution for application in the manufacturing process. Also, the reproducibility of the results is at a high level. Working with a free core is simple and reliable. The described solution complements and extends the sphere of forming
\end{abstract}

Keywords: Forming, cavity, solenoid, free core, unconventional methods

\section{INTRODUCTION}

In this paper, the focus is targeted at the issue of magnetic forming. This area is of great ecological interest. Its advantage is that the forming process carried out this way does not burden the environment in any way. The knowledge mentioned above in text is obtained from experiments realized in laboratory conditions. The bibliography reference is given to recent works and these probably satisfy the interest of our reader. The paper aims to verify the possibility of applying a unique tool when creating a cavity into a sample using a so-called application of free core forming. Further benefits gained from experimental work and its results are also expected.

\section{IN GENERAL}

For decades, the leading technology in manufacturing technology (production) is being occupied by the forming technology. The main advantage of forming is the considerable savings of materials which, at the current pressure on the greening of production (in general and worldwide), prove to be very suitable and appropriate. Another advantage of forming is its relatively easy process automation. The great importance of the forming technology is also in the fact that it enables a significant increase in labour productivity, which is manifested in particular by shortening the production cycle of production and reducing labour need intensity. However, the application of new knowledge to the production and the exploitation of the advantages of the forming technologies depends on the correct design of the forming tools. It is about applying new procedures, which mainly consist of the use of real knowledge, which is a massive potential of stimuli. Forming, in this case, takes place mainly in the so-called unstable tools. By this, we mean forming tools whose construction takes into account the use of new solutions, where all-metal tools are not needed. 
Nothing can be underestimated when applying the forming techniques. The way of the presented sphere itself belongs to the spectrum of unconventional technological processes of forming [1-11].

\subsection{Author's publications in the field of magnetic forming}

The author has been involved in the topic of the field of magnetic forming for several years and has been researching and researches primarily the forming of metal sheets using the magnetic field. He also dealt with the possibility of forming circumferential rings on a sheet metal output. He also pointed out the forming of the sheet in an open magnetic field and focused on the joining pipes using a magnetic field [12-15].

\section{DESIGN AND CONSTUCTION OF THE EXPERIMENTAL DEVICE}

There is in Figure 1 is an idea for the construction of an experimental device for carrying out experiments. Next, attention is paid to free core-forming while forming the cavities in lead samples. An experimental device was constructed and built, in which research work was carried out.

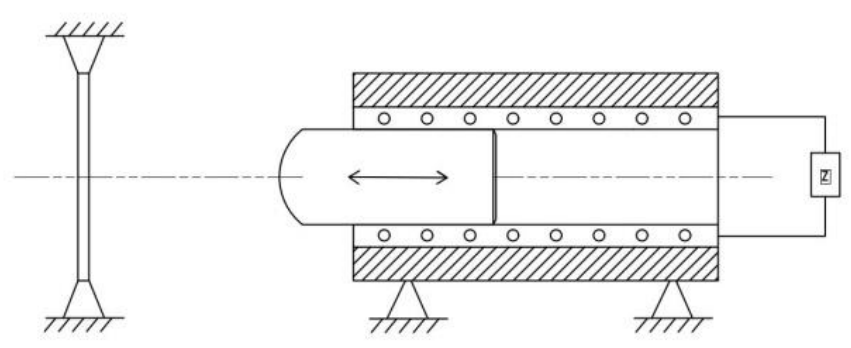

Figure 1 Scheme of forming using magnetic field with free core (punch)

\subsection{Electrical circuit forming device}

An essential part of the experimental device in both the first and the second case is the electric circuit, where a magnetic field (impulse) is created which forms the experimental material. As we can see in Figure 2, there is a circuit consisting of a relay, power supply and switch used [16].

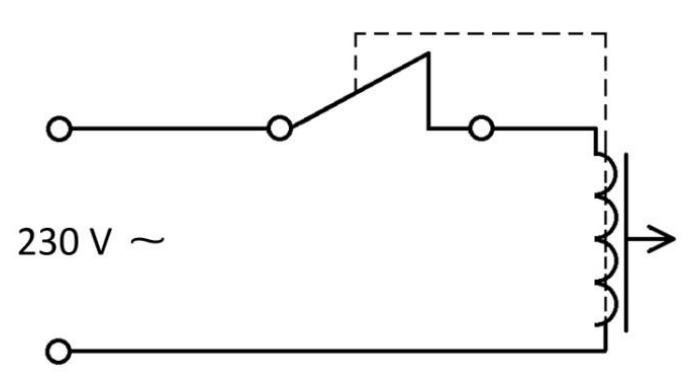

Figure 2 Scheme forming by Magnetic pulse

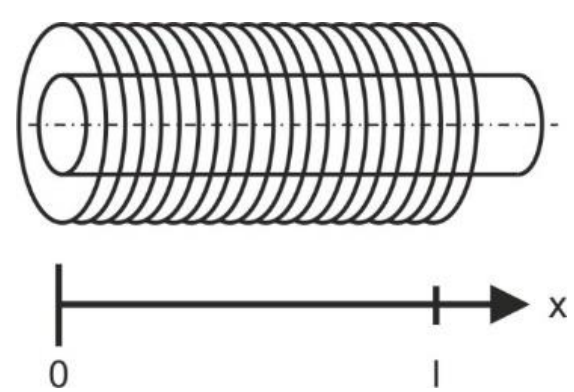

Figure 3 Forming scheme using

Forming using a magnetic field, or the forces exerted while the coil application can be divided into two main groups:

- $\quad$ forming with a free core, that is, where the core moves in a horizontal direction in the cavity of the solenoid and, upon contact (impact) on the formed material, its movement stops, 
- $\quad$ forming with a sprung core, wherein the core is connected to the functional unit using a conical spring. It ensures that the core is displaced to the initial position after the forming operation has been performed.

The paper aims to verify this method and in experimental work to achieve new knowledge and findings. These are then generalized to conclusions that can be used in further research in this field. Considering the behaviour of the free core in the cavity of the solenoid, a mathematical description of this phenomenon is given in the following paragraph.

\subsection{Description of the process of core movement in the solenoid's cavity}

It is necessary to examine the movement of the core in the cavity of the solenoid since it is directly dependent on how the active part that is coupled to the core will move.

Force is a derivative of energy relative to the position of the fitting. This requires expressing the change in inductance with position $L(\mathrm{x})$. We begin by defining a coordinate system, as shown in Figure 3.

At $x=0$ the armature is entirely in the coil. At $x=1$, the armature is at the inlet edge of the coil. For these two positions, inductance can be easily defined using the standard coil inductance approximation:

$$
\begin{aligned}
& L(0)=L_{0}=\frac{\mu_{r} \cdot \mu_{0} \cdot N^{2} \cdot A}{l} \\
& L(l)=L_{l}=\frac{L_{0}}{\mu_{r}}=\frac{\mu_{0} \cdot N^{2} \cdot A}{l}
\end{aligned}
$$

It may be advantageous to define I a little further out of the coil in order to avoid the armature of the edge of field B, thereby improving accuracy (2). However, to keep the simplicity, we will use the coil length $v(2)$ and provide an alternative way to make this adjustment below. $L(0)$ is much larger than $L(\Lambda$ because the relative permeability of the iron armature is much higher than the permeability of the free space. $L(x)$ will vary monotonously between the two extremes and the exact shape of this change with position depends on the design and shape of the solenoid. The exact model of this variation requires the creation of a detailed spatial model (such as the finite element model) of a solenoid that is a magnetic field. For our purposes, all we need here is a reasonable approximation for a cylindrical solenoid, and now there is an exponential decomposition:

$$
L(x)=L_{0} \cdot e^{-\frac{a}{l} \cdot x}
$$

Depending on the need, this value has a value of $L_{0}$ at $x=0$ and we want to select the $\alpha$ parameter so that $L(t)=L_{0} / u$ :

$$
\alpha=\ln \left(\mu_{r}\right)
$$

An $\alpha$ value that is slightly less than this but greater than the unity will have the same effect as the movement $I$ of the outer coil. Now the power can be deduced and expressed as:

$$
\begin{aligned}
& F(x)=\frac{V^{2}}{2 \cdot R^{2}} \cdot \frac{\alpha}{l} \cdot L_{0} \cdot e^{-\frac{\alpha}{l} \cdot x} \\
& F(x)=\frac{I^{2} \cdot \mu_{r} \cdot \mu_{0} \cdot N^{2} \cdot A}{2 \cdot l^{2}} \cdot \alpha \cdot e^{-\frac{\alpha}{l} \cdot x}
\end{aligned}
$$

In relation, it means $A$ - area inside the solenoid $\left(\mathrm{mm}^{2}\right), N$ - number of windings of the solenoid, I - current (A). 
The calculation was derived from the contribution [17]. Here the author provides $V=I / R$, which is discussed in the previous text.

\section{EXPERIMENTAL PART}

The experimental work was carried out on the own device presented in Figure 4. Ten specimens were formed. The forming was applied with a free core, forming lead samples of square shape with dimensions of $35 \times 35$ $\mathrm{mm}$ and thickness of $7 \mathrm{~mm}$.

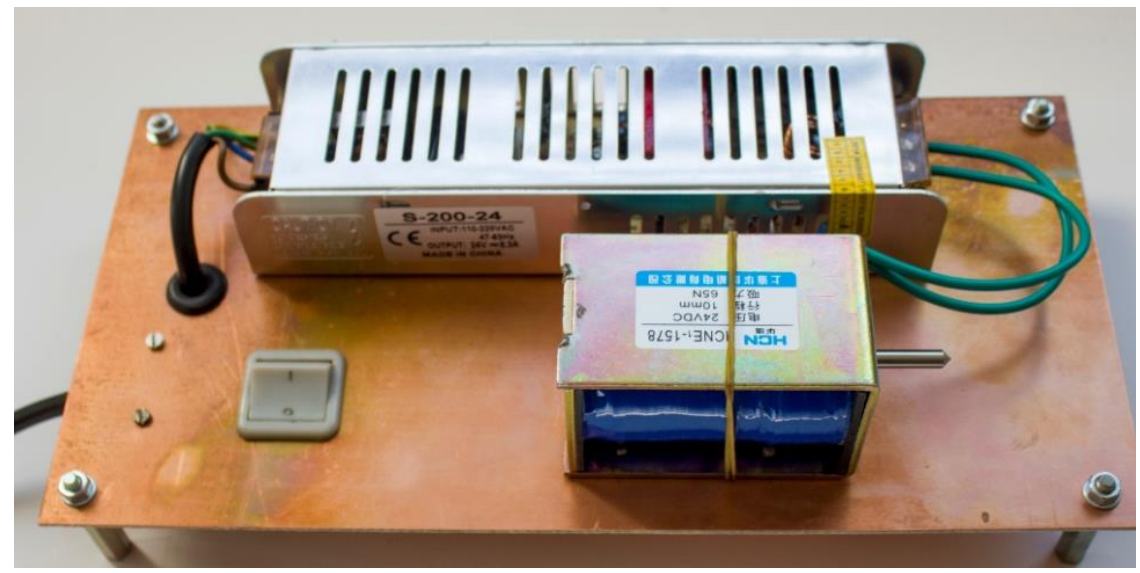

Figure 4 Device for experimental free-core forming used in the reality

\subsection{Experimental results}

The results obtained in experiments with the application of a free core (punch) prove that such a method of forming is suitable for several reasons. The first is the speed of the process when the work itself is a period expressed in hundredths of seconds. In our case, it is $0.03 \mathrm{~s}$. The second advantage is in terms of ease of automation using this forming. The analysis of the results in Table 1 shows that this is a relatively stable process since the difference between the maximum value of $3.44 \mathrm{~mm}$ and the minimum value of $2.69 \mathrm{~mm}$ is at an indentation diameter of $0.77 \mathrm{~mm}$. The difference between the maximum value of $1.48 \mathrm{~mm}$ and the minimum value of $1.04 \mathrm{~mm}$ with the intrusion parameter is $0.44 \mathrm{~mm}$. The values for this section are balanced and stable. Samples were measured on a Dino-Lite device.

Table 1 Results of experiments (lead)

\begin{tabular}{|c|c|c|}
\hline Number of sample & $\begin{array}{c}\text { Diameter impress } \\
(\mathbf{m m})\end{array}$ & $\begin{array}{c}\text { Intrusion } \\
(\mathbf{m m})\end{array}$ \\
\hline 1 & 2.69 & 1.04 \\
\hline 2 & 2.77 & 1.06 \\
\hline 3 & 2.94 & 1.32 \\
\hline 4 & 3.44 & 1.31 \\
\hline 5 & 3.08 & 1.31 \\
\hline 6 & 3.02 & 1.25 \\
\hline 7 & 2.83 & 1.40 \\
\hline 8 & 2.88 & 1.30 \\
\hline 9 & 2.74 & 1.45 \\
\hline 10 & 3.10 & 1.48 \\
\hline
\end{tabular}




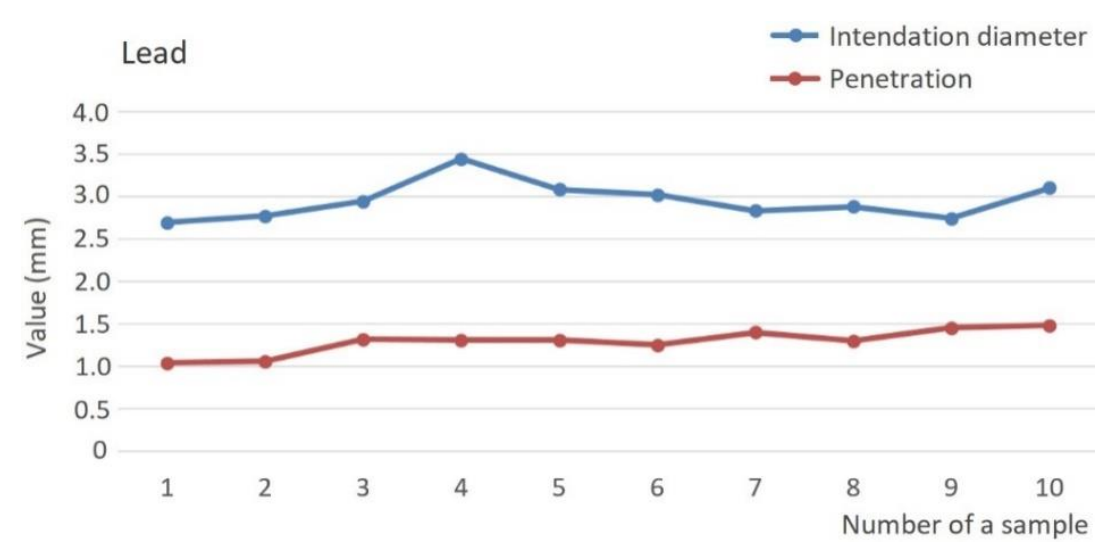

Figure 5 Graph for Table 1

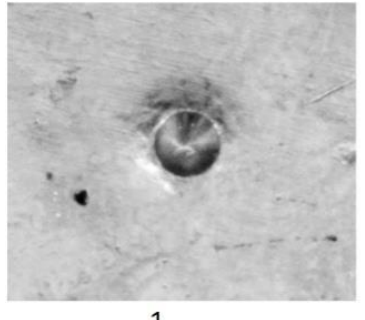

1

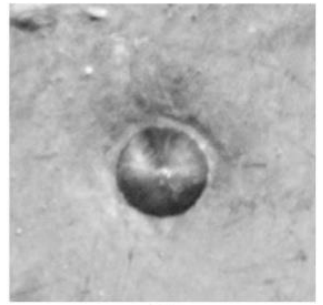

2

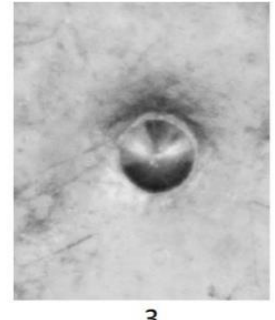

3

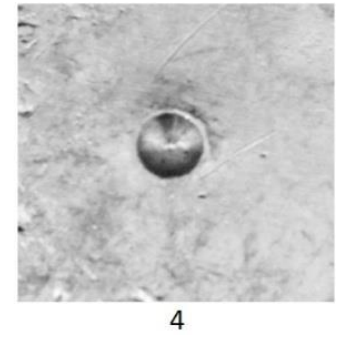

Figure 6 Samples after cavity formation, non-etched, magnified 10x: 1 - diameter 2.68 mm, 2 - diameter $3.10 \mathrm{~mm}, 3$ - diameter $2.88 \mathrm{~mm}, 4$ - diameter $2.74 \mathrm{~mm}$

\section{DISCUSSION}

Forming in the volume spectrum is possible and proves to be productive and also convenient in the formation of cavities and indentations, reliefs and surface treatments. The lead samples have quite suitably served as a model material for this area and on their basis it can be concluded that the solution is suitable for industrial use (Of course, when using more powerful devices).

It is also important to mention the ecological aspect of the process. The necessary electricity supplied to the device may also come from an alternative source, and the workplace does not burden the environment, such as e.g., in the case of using a classic forming device and forming all-metal tools.

\subsection{Reached goal}

- design of the original experimental forming device and its verification under experimental conditions,

- $\quad$ generating the equation of motion and determining the forming force when applying free core forming.

\section{CONCLUSION}

In this paper, we focused on the use of magnetic phenomena in metal forming technology. The objectives of the paper can be assessed as achieved and fully met. The original device was developed and constructed to ensure that cavity formation experiments were performed in the sample. This phenomenon will reliably achieve the desired forming effect. The laboratory experimental solution has shown the way how to apply physical knowledge in industrial production conveniently.

It has been confirmed that a reasonably simple solution with the application of a magnetic field will ensure accurate, quick and high-quality cavity formation in metallic materials. The results achieved also confirmed the suitability of the mentioned solution for the application in the manufacturing process. Cavity formation is one 
of the most critical work in the production of e.g., tools with cavities. The realization of this kind of work combines several advantages: speed of production, accuracy and very good final quality of cavities. Also, the reproducibility of the results is at a high level. The described solution complements and extends the sphere of forming in the area of volume forming. The published results in the text of the paper will surely be a reasonable basis for further research work in this area.

\section{REFERENCES}

[1] GOLOVASCHENKO, S.F. Electromagnetic Forming and Joining for Automotive Applications [online]. [viewed 2020-01-13]. Available from:

https://www.researchgate.net/publication/43057078 Electromagnetic Forming and Joining for Automotive App lications.

[2] VANHUNSEL, P. Groove design for form fit joints made by electromagnetic pulse clamping. Susuainable Construction and Design. 2011, pp. 432-441.

[3] ZHENGUA, M. Effects of process parameters on warm electromagnetic hybrid forming of magnesium alloy sheets. Journal of Material Processing Technology, vol. 211, 2011, pp. 863-867.

[4] HAI-PING, Y., CHUN-FANG, L. Effects of coil length on tube compression in electromagnetic forming. Trans. Nonferrous Met. Soc. China, 2007, vol. 17, pp. 1270-1275.

[5] KRAUSEL, V., SCHAFFER, R., ENGELBRECHT, I. Gepulste electromagnetische Felder schneiden hochfest Bleche. Maschnenmarkt, 2010, no. 4, pp. 26-29.

[6] WOODWARD, SX., WEDDLING, CH., DAEHN, G., PSYK, V. Production of low-volume aviation components using disposable electromagnetic actuators. Journal of Material Processing Technology, 2011, vol. 211, pp. 886895.

[7] SHANG, J. Agile manufacturing of a micro- embossed case by a two-step electromagnetic forming process. Journal of Materials Processing Technology, 2007, vol. 190, pp. 41-50.

[8] OKOYE, C.N., JIANG, J.H., HU, Z.D. Application of electromagnetic-assisted stamping (EMAS) technique in incremental sheet metal forming. International Journal of Machine Tools and Manufacture, 2006, vol. 46, pp. 1248-1252.

[9] UNGER, J., STIEMER, M., SVENDSEN, B., BLUM, H. Multified modeling of electromagnetic metal forming process. Journal of Materials Processing Technology, 2006, Vol. 177, pp. 270-273.

[10] PSYK, V., RISCH, D., KINSEY, B.L., TEKKAYA, A.E., KLEINER, M. Electromagnetic forming - a Review. Journal of Materials Processing Technology, vol. 211, no. 5, 2001, 787-829.

[11] MORAVEC, J. Electromagnetic sheet metal forming, Elektromagnetische blechumformung. University of Žilina, 2019.

[12] SCHIMPF, P.H. A Detailed Explanation of Solenoid Force. Recent Trends in Engineering and Technology, vol. 8 no. 2, 2013.

[13] KURKA, P. Innovative Forming Technologies in Car Body Structures, $25^{\text {th }}$ Anniversary International Conference on Metallurgy and materials - METAL 2016, May 25-27 2016, Brno, pp. 310-315. ISSN 978-80-87294-67-3.

[14] BELLITO, C., BAUER, E. M., RIGHINI, G. On the crystal structures and magnetism of some hybrid organicinorganic metal organo phosphonates, Anorganica Chemica Acta 361, 2008, pp. 3785-3799.

[15] MORAVEC, J. Electromagnetic forming of thin-walled tubes, International Conference on Metallurgy and materials - METAL 2017, May 24-26 2017, Brno, pp. 326-331, ISBN 978-80-87294-79-6.

[16] MORAVEC, J. Unconventional Method of Forming Circumferential Rings on Sheet Metal parts, $27^{\text {th }}$ International Conference on Metallurgy and materials - METAL 2018, May 23-25 2018, Brno, pp. 249-254, ISBN 978-8087294-84-0.

[17] MORAVEC, J. Magnetic forming, monograph ZU Žilina 2018, p. 113. ISBN 978-80-554-1498-0. 